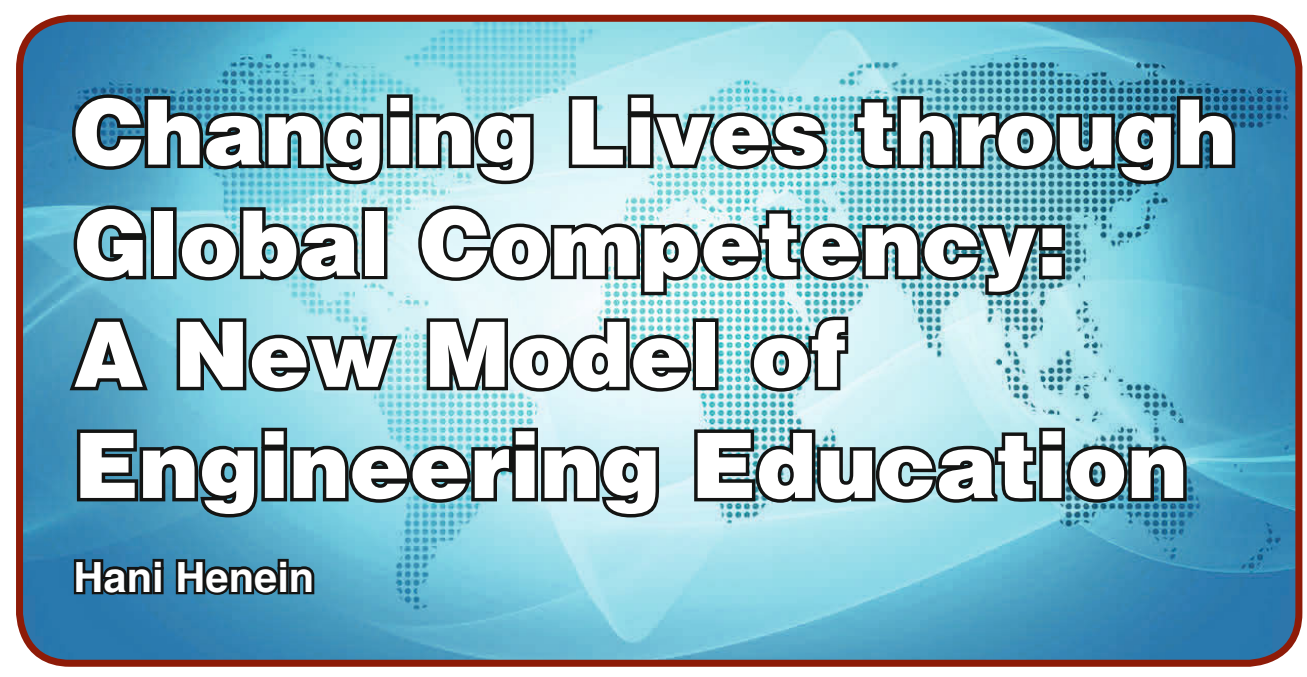

\section{Background and Historical Perspective}

The educational approaches of an engineer have evolved over the centuries. From Imhotep (2650 to 2600 BC), the first known engineer, up to the Renaissance, engineers learned rules and methods for designing and building structures, implements, and military machines through an apprenticeship model. With the birth of the Renaissance (14th to the 17th century A.D.) and the scientific method, the education of an engineer underwent a revolutionary change.

In the 18th century, France established the system of les Grandes Écoles, where engineering education was based on the teaching of science and mathematics fundamentals. In Canada, the first engineering programs-McGill University established in 1871 and the University of Toronto, established in 1873-followed the French fundamentals model. In 1957, the University of Waterloo introduced a $100 \%$ co-operative education program (coop) that combined the fundamentals model and the apprenticeship model.

The University of Alberta (UofA) runs the second oldest co-op program in Canada, having established it in 1981.Most engineering programs in Canada now have some form of co-op in the curriculum.

Canada's economy is traditionally based on its natural resources, with minerals, oil and gas, and lumber presently among its leading exports. Over time, the United States became Canada's largest trading partner due to its proximity, the demand for goods, and growth of the
U.S. economy. While trade with the U.S. is still very strong, Canada's percentage of exports to the United States has decreased, with projections pointing to a further decrease in the years ahead. More corporations in Canada are doing business with non-English speaking countries and many recent investments in the Canadian economy are from foreign sources. Today and increasingly in the future, chances are good that a Canadian engineer will be working with non-U.S. customers, while fellow employees will also likely be overseas, with work sharing across continents becoming more and more common. To be ready for this type of employment, engineers need additional training in global competency.

To help prepare UofA students for these changing demands, I initiated an international work placement program in 2002 within the UofA Faculty of Engineering, with the administrative assistance of UofA International (UAI). With the support of my international colleagues, I identify work placements in overseas research institutes. The placements are largely research focused and typically last four months or eight months. In return, I accept international students for six-month internships. To date, nearly 100 students have participated in this program and have attended Dresden University of Technology (Germany), Université de Lorraine-École des Mines de Nancy and École National des Industries Chemique (France), University of Bremen (Germany), Norwegian University of Science and Technology (Norway) and

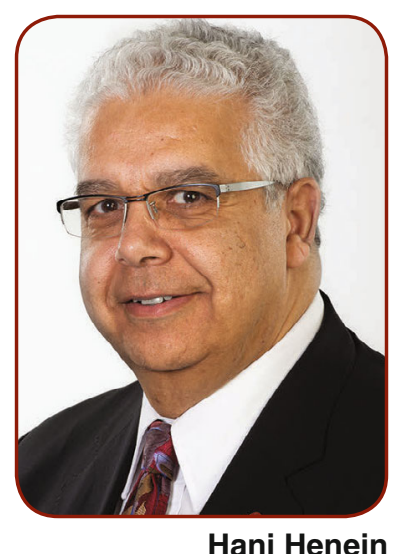

Hani Henein

\section{About This} Article

"Changing Lives through Global

Competency: A New

Model of Engineering

Education" is one of a series of

occasional articles

by TMS members

on experiences, insights, and ideas for advancing educational innovation in

minerals, metals, and materials science and engineering, that can be applied, evaluated, and evolved further. The development of this feature series is a special project of the TMS Education Committee." 


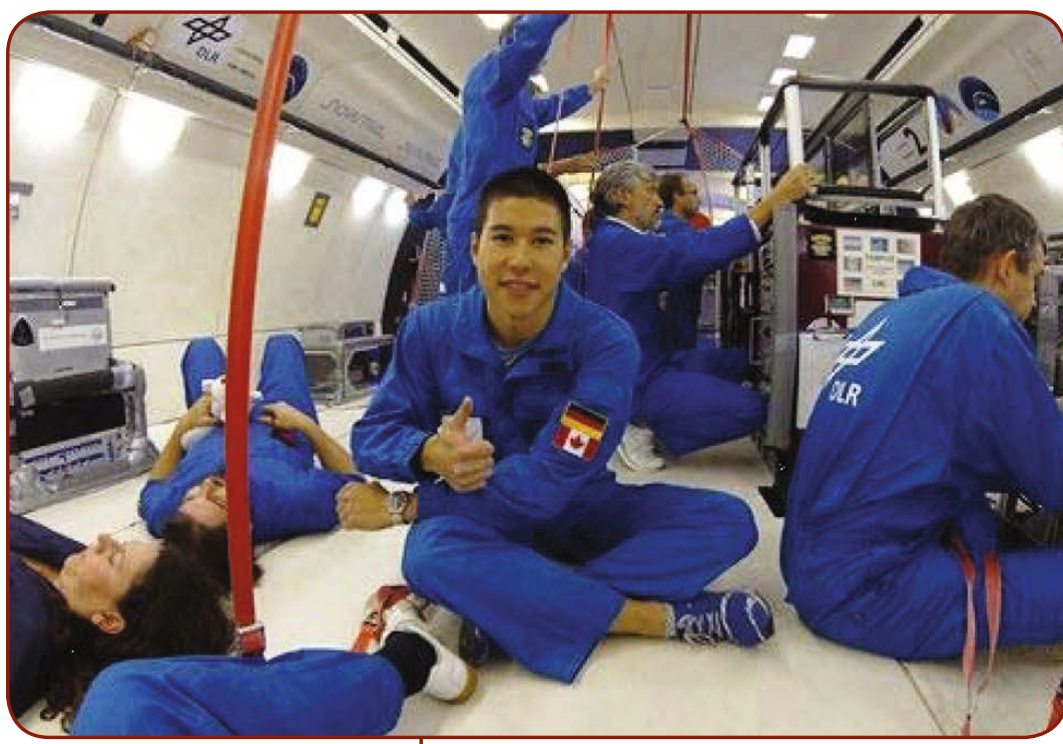

Brandon Kwong, a University of Alberta co-op student, participated in a parabolic flight while supervising a University of Alberta experiment in microgravity as part of his work placement in Germany (2013).
Hokkaido University (Sapporo, Japan). These students represent a variety of engineering disciplines, including civil, mechanical, chemical, and materials. Half of the students participating in this program continue to graduate school to earn at least a master's degree. More recently, students have been recruited to work for the German Aerospace Centre in Cologne and the Fraunhofer-Institut für Fertigungstechnik und Angewandte Materialforschung in Dresden.

\section{The Mechanics of Student Selection}

The UofA career placement systems, the UAI (Go Abroad) web sites, and the co-op office in the Faculty of Engineering all help promote the availability and value of this program to students. UAI also assists with students interviews. Undergraduate juniors tend to be the most interested in this program. Qualified students are then connected with the potential host. If the selection is acceptable to both, the students are responsible for securing their own visas and travel documents for the country of their internship and are required to participate in a pre-departure session. The session provides an overview of the psychological, financial, risk management, and daily considerations of moving to a new country and living in a different culture, with alumni of the program sharing their experiences. Both UAI and I oversee this process.

Typically, local governments limit the maximum a student can earn as an intern.
This usually is not enough to live on, so UofA offers two programs to help students with financial support to go abroad. One is a group award and the other an individual award. The former requires the faculty member to apply and is skewed to favor courses where registered students travel abroad as a group. Coordinating the internal deadlines for individual awards with the declared needs of the hosts can be challenging, since this information is usually only known six months in advance of the internship. We try to supplement the internship stipend with about $\$ 2,000$ for a four month stay, and $\$ 3,500$ for an eight month stay. Students generally still need to dip into their savings to participate in this opportunity.

Although the internships require fulltime work with the host organization, the students pack in a lot of travel on the weekends. Also, the host organizations tend to be generous with vacation time, as they are aware that the students are there for the experience and not only for the job. Students are offered foreign language courses to help begin immersion into the local culture of their internship experience. When students are registered in the co-op program they receive credit for the UofA Work Experience Course, according to the number of months that they are employed. The internship program is also offered to non co-op students. In process is a mechanism to give non co-op students credit for an international internship. Student demand for this program is growing, and we are currently placing about a dozen students per year.

For international exchange students to UofA, the UofA Immigration Office identifies the proper documentation needed by the incoming student. The current system requires UofA to have a formal agreement with the institution where we send and receive students. This is a critical step, but a very time-consuming process. The UofA host pays the incoming students from their research grants or contracts at about $\$ 1,500$ per month. The number of incoming students is limited to about four per year.

\section{Student Experiences}

All of the students participating in this program return with a highly positive 
experience and their lives transformed. One such example is Jordan Ramsay, who spent eight months at Université de Lorraine in Nancy, France. Upon graduation, she applied and successfully received a scholarship to pursue a Ph.D. at Churchill College, Cambridge University. The value of the internship program can be summed up in Jordan's own words, "Working in Nancy for eight months really gave me the push to apply for the scholarship. It meant a lot to me and was truly the experience of a lifetime."

Such is the experience of every student who participates in this program. The common theme is that they pursue a path in life that is unique and strongly international in flavor. I take great personal satisfaction in being a part of the positive transformation in the lives of these students. It reminds me that a university education is not just about the academics, but also about opening the world to students, our society's future leaders. This effort brings great honor and prestige to our university.

\section{Lessons Learned}

There are three major challenges to offering and running this type of international learning program. The first is the enormous time it takes to formulate and develop agreements between universities. Because universities are such complex entities, agreements must be vetted by departments, faculties, and many administrative units (risk management, immigration, registrar, etc.) of both partners. In a large university such as the UofA, it could take three to four years to complete these processes. Then, as soon as the ink is dry on one agreement, the process begins again for the renewal. Universities need to develop more efficient approaches to the development of such agreements in order to focus the process on sending more students abroad.

The second challenge is funding for students while they are living abroad. Many governments limit the amount of funds that can be paid to a foreign student working an internship. Such amounts do not reasonably cover living expenses. The fact that students need to also save funds for their upcoming academic year complicates the situation.

The third challenge is sustainability. The

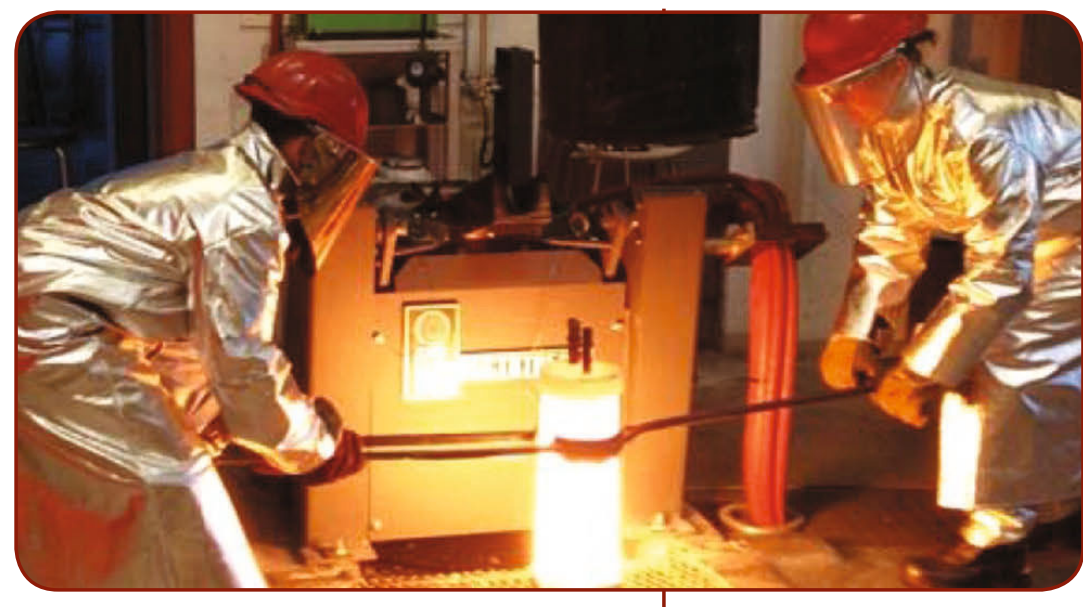

program described in this article has been so successful that UAI staff are always looking for partnership programs to offer additional internships for engineering students. At the University of Alberta, in addition to the program that I initiated in 2002, there are the Queen Elizabeth II Scholarship Program, the Berlin Initiative, the Saxony Program, and several others. Our challenge now at UofA is to coordinate these efforts and provide long-term sustainability of the global competency effort in a way that does not depend on one faculty member.

To achieve sustainability, the Department of Chemical and Materials Engineering is aiming to establish a Work Abroad Course and have it embraced by the Faculty of Engineering. In future, students will have the option to register for an abroad work experience course (with paid tuition). Such registration will be reviewed by the respective home department of the student to ensure equivalent quality to project courses taken at the UofA. Non co-op students will then be able to apply the course credit to replace a technical elective in their program of study at UofA. Co-op students will have this course designation appear in their transcript acknowledging their international work experience. Such developments will firmly establish global competency as the next critical component in the education of an engineer in the 21st century, building on the traditional models of fundamentals and apprenticeship.

Hani Henein is a professor in the Department of Chemical and Materials Engineering at the University of Alberta, Canada, and is the 2014 TMS President.
Tessa-Rae Omenlchenko, a University of Alberta student (right), assists with an experiment at the Norwegian Technical University of Science and Technology (2013). 